Prevalence and Evaluation of Iron Deficiency Anemia in Anemic Hospitalized Patients in Osogbo, Nigeria

\section{Esan $\mathrm{AJ}^{*}$}

Department of Haematology and Blood Transfusion Science, Federal Teaching Hospital, Ido-Ekiti, Nigeria

\begin{abstract}
\section{Introduction}

Iron deficiency is the most prevalent cause of nutritional anemia worldwide. Iron deficiency anemia occurs when the body has insufficient iron to support red blood cell production. The aim of the study is to determine the prevalence of iron deficiency anemia and to assess hematological indices with iron status in the affected patients.
\end{abstract}

\section{Methodology}

One hundred clinically sever anemic patients with hemoglobin concentration level less than $80 \mathrm{~g} / \mathrm{L}$ recently un-transfused at least one month to this study of both sex between age 0 and 65 years were selected for the study from Ladoke Akintola University Teaching Hospital, Osogbo and Asubiaro State Hospital, Osogbo. Hematological indices were analyzed using automated machine (Humacount); hemoglobin electrophoresis was determined using alkaline globin chain; serum iron and serum ferritin were also analyzed using advanced atomic absorption spectrophotometry.

\section{Results}

Out of 100 anemic patients, 40 were male and 60 were female; age group $0-15$ years and $16-30$ years had anemic prevalence of 30 and 38 respectively. 73 out of 100 anemic patients had iron deficient anemia; $24(32.9 \%)$ were male and $49(67.1 \%)$ were female.

\section{Conclusion}

Iron deficiency is the most common cause of anemia worldwide. This study showed that, iron deficiency anemia was common in both children and female of child bearing age and iron status in anemic patients with hemoglobinopaties were adequate.

Keywords: Anemia; Hemoglobin concentration; Iron deficiency

*Corresponding author: Esan AJ, Department of Haematology and Blood Transfusion Science, Federal Teaching Hospital, Ido-Ekiti, Nigeria, Tel: +234 8035477756; E-mail: ayodelejacob4u@gmail.com

Citation: Esan AJ (2016) Prevalence and Evaluation of Iron Deficiency Anemia in Anemic Hospitalized Patients in Osogbo, Nigeria. J Hematol Blood Transfus Disord 3: 007.

Received: June 09, 2016; Accepted: August 03, 2016; Published: August 17 , 2016

\section{Introduction}

Iron Deficiency Anemia (IDA) is the most prevalent cause of nutritional anemia. IDA occurs when the body has insufficient iron to support red blood cell production [1,2]. World Health Organization defines anemia as: $\mathrm{Hb}<130 \mathrm{~g} / \mathrm{L}$ in men over 15 years old; $\mathrm{Hb}<120 \mathrm{~g} / \mathrm{L}$ in non-pregnant women over 15 years old; $\mathrm{Hb}<120 \mathrm{~g} / \mathrm{L}$ in children aged 12-14 years [1]. Anemia can be raised in altitudes above 3000 feet because of lower oxygen partial pressure or due to reduction in oxygen saturation of blood, and an increase in red blood cell production. Cigarette smoking also raises the cut-point for anemia because carboxyhemoglobin formed from carbon monoxide during smoking has no oxygen-carrying capacity [1]. Iron deficiency anemia is characterized by a defect in hemoglobin synthesis, resulting in red blood cells that are abnormally small (microcytic) and contain a decreased amount of hemoglobin (hypochromic) [3]. The capacity of the blood to deliver oxygen to body cells and tissues is thus reduced. Iron deficiency is associated with depleted stores and abnormalities in iron metabolism and red blood cell biochemistry. Adolescents are vulnerable to iron deficiency because of increased iron requirements related to rapid growth. Iron needs are highest in males during peak pubertal development because of a greater increase in blood volume, muscle mass and myoglobin [1,4]. After menarche, iron needs continue to remain high in females because of menstrual blood loss, which averages about $20 \mathrm{mg}$ of iron per month, but may be as high as $58 \mathrm{mg}$ in some individuals. Oral contraceptives decrease menstrual losses, while some intrauterine devices may increase losses [5]. Iron deficiency with anemia in infants (0-12 months) and preschool children (1-5 years) resulted into developmental delays and behavioral disturbance for example decreased motor activity and social interactions. These developmental delays may persist past school age (5 years) if the iron deficiency is not fully reversed [6]. Iron is essential to all cells, functions of iron include involvement in energy metabolism, gene regulation, cell growth and differentiation, oxygen binding and transport, muscle oxygen use and storage, enzyme reactions, neurotransmitter synthesis, and protein synthesis $[1,3,5]$. Total amount of iron in the body is determined by the intake, loss and storage of iron [7]. Regulation of iron balance occur mainly in the gastrointestinal track through absorption, when the adsorptive mechanism is operating normally, a person maintains functional iron and tends to established iron store. Capacity of the body to absorb iron from the diet depends on the amount of iron in the body, the rate of red blood cell production, the amount and kind of iron in the diet (ferrous form $\left(\mathrm{fe}^{2+}\right)$ and the presence of absorption enhancers (vitamin $\mathrm{C}$ and hydrochloric acid). Iron absorption is increased when the body's iron store is low and decrease in iron absorption occurs when stored iron is sufficient [7]. Absorption of iron actively occurs in the duodenum, stomach, ileum and colon [8]. Absorbed iron from small intestine is immediately combined in the blood plasma with beta-globins and apotransferrin to transferrin which transport iron in the plasma into tissue that have transferrin receptor especially erythroblast in the bone marrow where hemoglobin is being synthesized or it may be transported to the reticuloendothelia system (liver or spleen) where iron is being stored 
as ferritin or hemosiderin [9]. Iron deficiency occurs when the dietary iron intake is insufficient (especially in high consumption of non haem-iron) or poor iron absorption due to iron absorption inhibiting factors such as tannine in tea which reduces hemoglobin synthesis [10]. It may also be due to excessive body demand for example prematurity, growth in children, lactation, pregnancy especially with twins due to expansion of blood volume by approximately $35 \%$ and growth of the fetus placenta and other maternal tissues which increase the demand for iron threefold in the second and third trimester [11] or iron loss through Gastrointestinal Tract (GIT) such as colon cancer which causes loss of blood in stool, gastric cancer, peptic ulcer. The commonest cause of iron deficiency in adult is by blood loss which may be physiological in menstruating women especially in blood greater than or equal to $80 \mathrm{ml} / \mathrm{month}$ or uses of an intrauterine device which increased menstrual blood loss, hookworm infestation especially in rural area [7]. Although there is no single laboratory test that specifically indicates iron deficiency anemia, several tests are used to determine iron status and the presence of anemia. Iron status can be measured using hematological and biochemical indices, each parameters of iron status reflects changes in different body iron compartments and are affected at different levels of iron depletion. To identify iron deficiency anemia, a reduction in Mean Cell Volume (MCV) below cut-off value of $80 \mathrm{fL}$ is an indication of iron deficiency anemia once thalassemia and anemia of chronic disease have been excluded. Red cell Distribution Width (RDW) is an index of the variation in the size of the red blood cells and can be used to detect subtle degrees of anisocytosis. An elevated red cell distribution width greater than $14.5 \%$ appears to be the earliest hematological manifestation of iron deficiency. A low mean cell volume together with an increased red cell distribution width is strongly suggestive of iron deficiency and when accompanied by an increase erythrocyte protoporphyrin can be considered diagnostic. A low serum ferritin $(<15 \mu \mathrm{g} / \mathrm{L})$, in addition to a low hemoglobin concentration of $<0.8 \mathrm{~g} / \mathrm{dL}$ or hematocrit $<20 \%$, confirms the diagnosis of iron deficiency anemia [1,3]. An elevated serum Transferrin Receptor concentration (TfR) $(>8.5 \mathrm{mg} / \mathrm{L})$ is an early and sensitive indicator of iron deficiency $[3,4]$. Serum TfR concentration remains normal when chronic disease, inflammation or infection are present, distinguishing iron deficiency anemia from anemia of chronic disease $[14,15]$. Failure to investigate IDA appropriately in primary care can cause significant delay in final diagnosis, with associated morbidity [12-15]. The aim of the study is to determine the prevalence of iron deficiency anemia and to assess hematological indices with iron status in the affected patients.

\section{Materials and Methods}

\section{Subjects, study design and sample collection}

One hundred clinically sever anemic patients with hemoglobin concentration level less than $8 \mathrm{~g} / \mathrm{dL}$ recently un-transfused at least one month to this study of both sex between age 0 and 65 years were selected from Ladoke Akintola University Teaching Hospital, Osogbo and Asubiaro State Hospital, Osogbo with ethical approval obtained. Ten apparently healthy subjects of either sex between ages 0 and 65 years were selected for controls. $5 \mathrm{ml}$ of venous blood samples were collected from each participants, $2 \mathrm{ml}$ was dispensed into dry di-potassium Ethylene Diamine Tetera Acetic acid (K $\mathrm{K}_{2}$ EDTA) bottles for the analysis of red blood cell indices, red cell distribution width, haemoglobin concentration, packed cell volume using automated machine (Humacount); thin blood film was made from dry di-potassium Ethylene Diamine Tetera Acetic acid ( $\mathrm{K}_{2}$ EDTA) bottles for every patient and stained using Leishman technique. Hemoglobin electrophoresis was determine using alkaline globin chain; $3 \mathrm{ml}$ of blood sample was dispensed into plain bottles for serum iron and serum ferritin analysis using advanced instrumentation in water analysis (atomic absorption spectrophotometry). Data obtained were analyzed using (SPSS version 16).

\section{Methodology}

Red blood cell indices, red cell distribution width, hemoglobin concentration, packed cell volume were analyzed using hematology analyzer (Human count) as described by the manufacturer [16]. Thin blood film was made from dry di-potassium Ethylene Diamine Tetera Acetic acid ( $\mathrm{K}_{2}$ EDTA) bottles for every patient and stained using Leishman technique [17]. Serum iron and serum ferritin were estimated using advanced instrumentation in water analysis (atomic absorption spectrophotometry; Buck 200 model) method; the procedure was as described by Adindu Steve Ogamba [18]. $0.3 \mathrm{ml}$ of blood sample was used to prepared hemolysate by centrifuge at $3000 \mathrm{~g}$ for ten minutes with Hittich universal bench centrifuge, model 1200. Plasma was aspirated off while the precipitate (blood cell layer) was resuspended in equal volume of normal saline $(0.85 \% \mathrm{NaCl})$ for washing. The washing was repeated three times and finally re-suspended in equal volume of normal saline. The red blood cell suspension $(40 \mu \mathrm{l})$ was mixed with equal volume of distilled water to lyse the blood cell. The resulting hemoglobin lysate (the lysate) was used for hemoglobin genotype determination to rule out anemia due to hemoglobinopathy [19]. The method described by Brown was used for haemoglobin electrophoresis. A small quantity of hemolysate of venous blood from each of the subject was placed on a cellulose acetate membrane and carefully introduced into the electrophoretic tank containing tris-EDTA-borate buffer at $\mathrm{pH}$ 8.6. Electrophoretic separation was then allowed to operate for 15 to 20 minutes at an electromotive force (e.m.f) of $160 \mathrm{v}$. The results were read immediately. Hemolysate from blood samples of known haemoglobin (AA, AS, AC, SC, CC and SS) were run as controls.

\section{Results}

Table 1, shows age and sex distribution in anemic patients, diagnosed iron deficient anemic patients and control subjects. Out of 100 anemic patients, 40 were male and 60 were female; age group 0-15 years and 16-30 years had prevalence of 30 and 38 respectively. 73 out of 100 anemic patients were iron deficient anemia; 24 (32.9\%) were male and $49(67.1 \%)$ were female, age group $0-15$ years and $16-30$ years had prevalence of $27(30.0 \%)$ and $30(41.1 \%)$ respectively among diagnosed iron deficient anemia. In control subjects, 4 were male and 6 were female.

Table 2, shows hematological indices and iron status in anemic patients and control subjects. The comparison between anemic patients and control subjects show significant difference $(\mathrm{p}<0.05)$ in hematological indices and iron status; this confirm that tested patients were truly anemic with iron deficiency anemia. Based on the parameters estimated to diagnosed iron deficiency anemia, anemia is common to all the tested patients but iron deficiency anemia is present in 73 patients, the remaining 27 anemic patients were due to hemoglobinopathies and other chronic ailments as observed in the clinical details of the patients who really need blood transfusion to increase oxygen carrying capacity in the red cell. 
Citation: Esan AJ (2016) Prevalence and Evaluation of Iron Deficiency Anemia in Anemic Hospitalized Patients in Osogbo, Nigeria. J Hematol Blood Transfus Disord 3: 007.

- Page 3 of $6 \bullet$

\begin{tabular}{|c|c|c|c|c|c|c|c|}
\hline \multirow[t]{2}{*}{ Subjects } & \multicolumn{5}{|c|}{ Age } & \multicolumn{2}{|c|}{ Sex } \\
\hline & $0-15$ & $16-30$ & $31-45$ & $46-60$ & $61-75$ & Male & Female \\
\hline $\begin{array}{l}\text { Anemic } \\
\text { Patients } \\
(\mathrm{N}=100)\end{array}$ & 30 & 38 & 17 & 11 & 4 & 40 & 60 \\
\hline $\begin{array}{l}\text { Iron Deficient } \\
\text { Patients } \\
(\mathrm{N}=73)\end{array}$ & $\begin{array}{c}27 \\
(37.0 \%)\end{array}$ & $\begin{array}{c}30 \\
(41.1 \%)\end{array}$ & $\begin{array}{c}9 \\
(12.3 \%)\end{array}$ & $\begin{array}{c}4 \\
(5.5 \%)\end{array}$ & $\begin{array}{c}3 \\
(4.1 \%)\end{array}$ & $\begin{array}{c}24 \\
(32.9 \%)\end{array}$ & $\begin{array}{c}49 \\
(67.1 \%)\end{array}$ \\
\hline $\begin{array}{l}\text { Control } \\
\text { Subjects } \\
(N=10)\end{array}$ & $\begin{array}{c}3 \\
(30.0 \%)\end{array}$ & $\begin{array}{c}3 \\
(30.0 \%)\end{array}$ & $\begin{array}{c}3 \\
(30.0 \%)\end{array}$ & $\begin{array}{c}1 \\
(10.0 \%)\end{array}$ & - & 4 & 6 \\
\hline
\end{tabular}

Table 1: Age and sex distribution in anemic patients, iron deficient patients and control subjects.

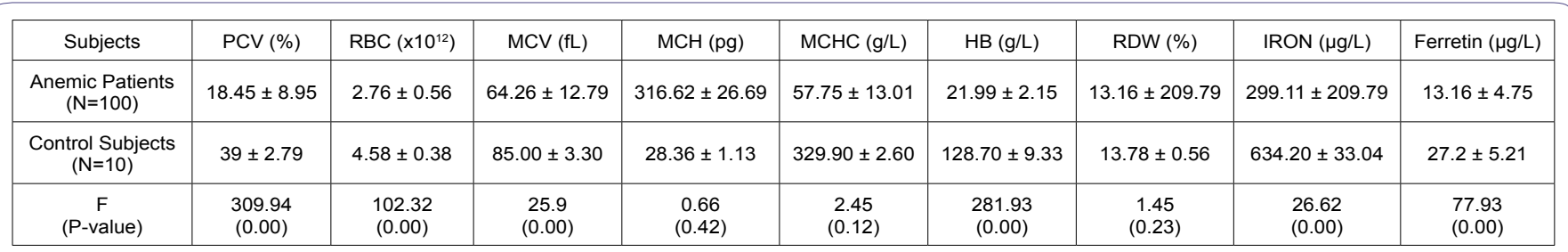

Table 2: Hematological indices and iron status in anemic patients and control subjects.

$P<0.05$ is consider statistically significance, $P>0.05$ is consider statistically not significant

Table 3, shows hematological indices and iron status in hemoglobin variants of anemic patients. Mean \pm SD of serum iron and serum ferritin in $\mathrm{Hb}$ SS, Hb SC and $\mathrm{Hb}$ CC were higher compared to other hemoglobin genotype variants, there is significant difference $(\mathrm{p}<0.05)$ in serum iron and serum ferritin. However, hematological indices show degree of anemia with no statistical significant difference. This confirms the fact that, iron is adequate in $\mathrm{Hb} \mathrm{SS}, \mathrm{Hb}$ $\mathrm{SC}$ and $\mathrm{Hb} \mathrm{CC}$ hemoglobinopathies as a result of frequent red blood cells breakdown and conservation of haemoglobin iron.

Table 4, hematological indices and iron status in sex distribution of diagnosed iron deficient anemic patient shows no statistical significance difference $(p>0.05)$ in both sex, this indicates that sex is not a factor to iron deficiency anemia, although the prevalence is higher in female than male due to peculiar factors in female like pregnancy, menstruation and lactation.

Table 5, shows hematological indices and iron status in age distribution among diagnosed iron deficient anemic patients. There is no statistical significance difference $(p>0.05)$ in age groups; this also indicates that iron deficiency anemia can occur in any age group though prevalence is higher in pre-school children, adolescent and child bearing age.

Blood film morphology among diagnosed iron deficient anemic patients in this study shows microcytic, hypochromic, anisocytosis and poikilocytosis. This red blood cell morphology is due to depleted iron stored.

\section{Discussion}

In this present study, 73 patients were diagnosed to be of iron deficiency with anemia, 27 patients were due to other cause of anemia who highly in need of blood transfusion to increase oxygen carrying capacity in the red blood cell. Similar to this study, Muhammad et al., 2005 reported 68 patients to be iron deficiency in moderate to severely anemia [20]. Contrary to this present study, Patel et al., 2005 reported that, 40 patients out of 100 anaemic patients were found to be iron deficiency with anemia [21]. Also, Ejaz et al., 2005 reported that out of 176 anemic patients studied, 86 (48.8\%) were diagnosed as iron deficiency anemia while 90 (51.1\%) were diagnosed as anemia of chronic disorder [22]. The comparison between anemic patients and control subjects in this study show a significant difference in hematological indices and iron status; this confirms that tested patients were truly anemic with iron deficiency. Iron deficiency anemia in the subjects tested may be due to poor socio economic condition, dietary or intestinal parasitic infestation or chronic ailments. In this present study, anemia is common in all age group especially in age group $0-15$ years and $16-30$ years with $30 \%$ and $38 \%$ respectively, this is similar to the finding by Metinkilin who reported that, aged 2-5 and 19-40 years with prevalence of $34.5 \%$ and $40.0 \%$ respectively were anemic [23]. Al-Dallal et al., 2003 reported that $20.3 \%$ of children between 12 and 59 months of age were anemic, 50\% of them had iron deficiency anemia, in woman of child bearing age, the prevalence of anemia was $32.3 \%$ with $70 \%$ of anemia due to iron deficiency [24]. The result of this study also, show high prevalence of iron deficiency with anemia within the age group 1-3years. There were two peaks $27(37.0 \%)$ and $30(41.1 \%)$ in a group $0-15$ and $16-30$ years respectively. This result is however in contrast to the result obtained by Muhammad et al., 2005 where majority of the patients with iron deficiency were aged between 20-60years (82.2\%) [20]; Metinkilin et al., 2002 also reported that iron deficiency anemia in age group 2-5 and $19-40$ years were $15.5 \%$ and $23.8 \%$ respectively [23]. A study conducted between 1976-1980, indicated that less than 50\% of children age 1-5 years and women in their child bearing years that had anemia by low hemoglobin concentration and hematocrit were iron deficient [25]. The prevalence rate of iron deficiency anemia in developed countries as reported by Looker et al., 1997 was 12\% for children between 0-14 years, $11 \%$ for women between $15-49$ years, $14 \%$ for pregnant women and 3\% for men between 15-59 years; in developing countries, about $50 \%$ prevalence rate of iron deficiency anemia in women and children while $25 \%$ in men were reported [26]. Bagchi et al., 2004 reported high prevalence rate of iron deficiency anemia among infants from six months onwards, $29 \%$ to over $60 \%$ in preschool children, $20 \%-70 \%$ in women of child bearing age from rural and urban backgrounds. Most study on adolescents have 
Citation: Esan AJ (2016) Prevalence and Evaluation of Iron Deficiency Anemia in Anemic Hospitalized Patients in Osogbo, Nigeria. J Hematol Blood Transfus Disord 3: 007 .

- Page 4 of 6 -

\begin{tabular}{|c|c|c|c|c|c|c|c|c|c|}
\hline Haemog Variants & PCV (\%) & $\operatorname{RBC}\left(\times 10^{12}\right)$ & $\operatorname{MCV}(f L)$ & $\mathrm{MCH}(\mathrm{pg})$ & $\mathrm{MCHC}(\mathrm{g} / \mathrm{L})$ & HB (g/L) & RDW (\%) & Iron $(\mu \mathrm{g} / \mathrm{L})$ & Ferritin $(\mu \mathrm{g} / \mathrm{L})$ \\
\hline $\begin{array}{c}A A \\
(N=55)\end{array}$ & $17.75 \pm 4.12$ & $2.75 \pm 0.49$ & $66.40 \pm 12.70$ & $23.62 \pm 17.99$ & $313.40 \pm 30.53$ & $58.18 \pm 13.18$ & $22.89 \pm 2.89$ & $313.03 \pm 222.87$ & $13.15 \pm 4.32$ \\
\hline $\begin{array}{c}\text { SS } \\
(N=7)\end{array}$ & $14.69 \pm 3.78$ & $2.50 \pm 0.87$ & $79.71 \pm 8.81$ & $21.79 \pm 2.20$ & $312.71 \pm 25.12$ & $48.29 \pm 13.59$ & $22.51 \pm 1.92$ & $441.43 \pm 266.29$ & $16.29 \pm 4.73$ \\
\hline $\begin{array}{c}A C \\
(N=11)\end{array}$ & $19.23 \pm 2.80$ & $3.13 \pm 0.47$ & $61.64 \pm 7.54$ & $31.69 \pm 3.91$ & $320.36 \pm 21.91$ & $61.73 \pm 10.79$ & $21.90 \pm 3.35$ & $215.82 \pm 152.22$ & $11.35 \pm 3.58$ \\
\hline $\begin{array}{c}S C \\
(N=4)\end{array}$ & $17.54 \pm 5.48$ & $2.80 \pm 0.97$ & $64.00 \pm 6.58$ & $20.55 \pm 1.29$ & $323.25 \pm 26.35$ & $57.75 \pm 20.53$ & $21.83 \pm 1.12$ & $322.50 \pm 195.35$ & $15.10 \pm 4.43$ \\
\hline $\begin{array}{c}\mathrm{CC} \\
(\mathrm{N}=2)\end{array}$ & $16.10 \pm 5.80$ & $2.52 \pm 0.53$ & $68.94 \pm 9.90$ & $20.50 \pm 1.41$ & $326.50 \pm 27.58$ & $52.00 \pm 14.14$ & $20.45 \pm 1.77$ & $341.23 \pm 214.04$ & $18.85 \pm 4.92$ \\
\hline$\underset{P \text {-value }}{F}$ & $\begin{array}{c}0.86 \\
(0.52)\end{array}$ & $\begin{array}{c}1.47 \\
(0.21)\end{array}$ & $\begin{array}{c}0.71 \\
(0.62)\end{array}$ & $\begin{array}{c}0.56 \\
(0.73)\end{array}$ & $\begin{array}{c}0.61 \\
(0.69)\end{array}$ & $\begin{array}{c}1 \\
(0.42)\end{array}$ & $\begin{array}{c}0.66 \\
(0.99)\end{array}$ & $\begin{array}{c}1.90 \\
(0.05)\end{array}$ & $\begin{array}{c}2.42 \\
(0.04)\end{array}$ \\
\hline
\end{tabular}

Table 3: Hematological indices and iron status on hemoglobin variants in anemic patients.

$P<0.05$ is consider statistically significance, $P>0.05$ is consider statistically not significant

\begin{tabular}{|c|c|c|c|c|c|c|c|c|c|}
\hline Sex & PCV (\%) & $\operatorname{RBC}\left(\times 10^{12}\right)$ & $\operatorname{MCV}(\mathrm{fL})$ & $\mathrm{MCH}(\mathrm{pg})$ & $\mathrm{MCHC}(\mathrm{g} / \mathrm{L})$ & HB (g/L) & RDW (\%) & IRON ( $\mu \mathrm{g} / \mathrm{L})$ & Ferritin $(\mu \mathrm{g} / \mathrm{L})$ \\
\hline $\begin{array}{c}\text { Male } \\
(\mathrm{N}=24)\end{array}$ & $17.14 \pm 4.06$ & $2.90 \pm 0.54$ & $58.67 \pm 8.01$ & $24.87 \pm 26.56$ & $314.46 \pm 27.21$ & $56.50 \pm 13.38$ & $30.40 \pm 4.28$ & $193.17 \pm 152.07$ & $10.64 \pm 2.75$ \\
\hline $\begin{array}{l}\text { Female } \\
(\mathrm{N}=49)\end{array}$ & $17.42 \pm 3.55$ & $2.89 \pm 0.58$ & $60.53 \pm 6.94$ & $22.11 \pm 18.72$ & $312.18 \pm 30.09$ & $50.02 \pm 12.70$ & $21.99 \pm 2.14$ & $214.24 \pm 110.39$ & $11.55 \pm 3.22$ \\
\hline $\begin{array}{c}F \\
\text { (p-value) }\end{array}$ & $\begin{array}{c}0.09 \\
(0.76)\end{array}$ & $\begin{array}{c}0.01 \\
(0.92)\end{array}$ & $\begin{array}{c}1.05 \\
(0.31)\end{array}$ & $\begin{array}{c}0.26 \\
(0.61)\end{array}$ & $\begin{array}{c}0.09 \\
(0.76)\end{array}$ & $\begin{array}{c}0.02 \\
(0.88)\end{array}$ & $\begin{array}{c}1.91 \\
(0.17)\end{array}$ & $\begin{array}{c}0.46 \\
(0.50)\end{array}$ & $\begin{array}{c}1.39 \\
(0.24)\end{array}$ \\
\hline
\end{tabular}

Table 4: Hematological indices and iron status in sex distribution of iron deficiency anemia.

$P<0.05$ is consider statistically significance, $P>0.05$ is consider statistically not significant

\begin{tabular}{|c|c|c|c|c|c|c|c|c|c|}
\hline Age & PCV (\%) & $\operatorname{RBC}\left(\times 10^{12}\right)$ & MCV (fL) & $\mathrm{MCH}(\mathrm{pg})$ & MCHC (g/L) & HB (g/L) & RDW (\%) & Iron $(\mu \mathrm{g} / \mathrm{L})$ & Ferritin $(\mu g / L)$ \\
\hline $\begin{array}{c}0-15 \\
(\mathrm{~N}=27)\end{array}$ & $17.13 \pm 4.22$ & $2.92 \pm 0.50$ & $58.74 \pm 6.91$ & $20.03 \pm 3.12$ & $307.81 \pm 30.12$ & $56.85 \pm 14.07$ & $23.34 \pm 2.31$ & $198.36 \pm 122.63$ & $10.33 \pm 2.14$ \\
\hline $\begin{array}{c}16-30 \\
(\mathrm{~N}=30)\end{array}$ & $17.44 \pm 3.24$ & $2.91 \pm 0.57$ & $60.43 \pm 6.20$ & $20.34 \pm 2.01$ & $321.57 \pm 31.34$ & $56.97 \pm 13.44$ & $22.19 \pm 1.97$ & $224.46 \pm 124.00$ & $11.98 \pm 3.11$ \\
\hline $\begin{array}{c}31-4 \\
(\mathrm{~N}=9)\end{array}$ & $17.80 \pm 3.70$ & $3.04 \pm 0.64$ & $58.00 \pm 5.83$ & $18.49 \pm 2.25$ & $314.22 \pm 31.16$ & $56.67 \pm 14.99$ & $22.27 \pm 2.45$ & $244.78 \pm 135.12$ & $11.34 \pm 2.80$ \\
\hline $\begin{array}{l}46-60 \\
(\mathrm{~N}=4)\end{array}$ & $16.59 \pm 3.34$ & $2.12 \pm 0.55$ & $65.00 \pm 4.55$ & $19.92 \pm 3.13$ & $300.50 \pm 31.86$ & $56.83 \pm 13.87$ & $21.10 \pm 1.88$ & $254.25 \pm 141.81$ & $12.87 \pm 2.99$ \\
\hline $\begin{array}{l}61-75 \\
(\mathrm{~N}=3)\end{array}$ & $19.13 \pm 3.58$ & $3.15 \pm 0.32$ & $64.33 \pm 6.66$ & $19.80 \pm 2.54$ & $306.33 \pm 32.01$ & $61.67 \pm 14.64$ & $21.60 \pm 2.23$ & $200.54 \pm 121.36$ & $11.78 \pm 2.22$ \\
\hline $\begin{array}{c}F \\
P \text {-value }\end{array}$ & $\begin{array}{c}1.54 \\
(0.20)\end{array}$ & $\begin{array}{c}2.38 \\
(0.06)\end{array}$ & $\begin{array}{c}1.13 \\
(0.35)\end{array}$ & $\begin{array}{c}0.84 \\
(0.50)\end{array}$ & $\begin{array}{c}1.61 \\
(0.18)\end{array}$ & $\begin{array}{c}1.75 \\
(0.15)\end{array}$ & $\begin{array}{c}0.36 \\
(0.84)\end{array}$ & $\begin{array}{c}1.07 \\
(0.38)\end{array}$ & $\begin{array}{c}1.65 \\
(0.17)\end{array}$ \\
\hline
\end{tabular}

Table 5: Hematological indices and iron status in age distribution among diagnosed iron deficient anemic patients.

$\mathrm{P}<0.05$ is consider statistically significance, $\mathrm{P}>0.05$ is consider statistically not significant

reported prevalence rate for iron deficiency anemia ranging from $30 \%-55 \%$ [10]. The high prevalence of iron deficiency with anemia in the age groups (children, adolescents and women of child bearing age) has been attributed to increased need for iron due to rapid growth in children, low intake of iron rich food or inappropriate dietary choices in children (0-15 years), poor iron absorption due to iron absorption inhibiting factors such as tannine in tea which reduces hemoglobin synthesis or inadequate iron absorption enhancers (vitamin $\mathrm{C}$ and hydrochloric acid) [10]. Some drugs can bind to iron and prevent absorption for example tetracycline and quinolones chelate with iron so that neither the antibiotic nor the iron is absorbed. Antacids and proton pump inhibitors may also impair absorption by raising gastric $\mathrm{pH}$, phytate (found in wholegrain cereals, nuts, seeds and legumes), polyphenols (found in tea and coffee) and calcium (in dairy products) impair iron absorption. Iron can be absorbed in the ferrous state much more readily than in the ferric state, Helicobacter pylori colonization appears to impair iron uptake and increase iron loss [12,27]. However, in elderly people with some underlying diseases causing blood loss such as intestinal parasite infection, menstruation especially in heavy menstrual blood loss greater than $80 \mathrm{ml}$ per month, blood loss through gastrointestinal track like colon cancer, gastric cancer, peptic ulcer [28]. Based on the parameters estimated for the diagnosis of iron deficiency anemia in this study, there is no statistical significant difference in the age groups; this indicates that iron deficiency anemia can occur in any age group though prevalence is higher in pre-school children, adolescent and women in child bearing age. In this present study, sex distribution in anemic patients were 40 male and 60 female while in iron deficient anemic patients $24(32.9 \%)$ were male and $49(67.15 \%)$ were female; there is no statistical significant difference in parameters estimated in both sex; this confirms that sex is not a factor to iron deficiency anemia, although the prevalence is higher in female than male due to peculiar 
Citation: Esan AJ (2016) Prevalence and Evaluation of Iron Deficiency Anemia in Anemic Hospitalized Patients in Osogbo, Nigeria. J Hematol Blood Transfus Disord 3: 007.

factors in female like pregnancy, menstruation and lactation. Similar to this present study, Muhammad et al., 2005 reported prevalence rates of iron deficiency anemia in males and female to be 27 (39.71\%) and $41(60.29 \%)$ respectively [20], Patel et al., 2005 also stated that females were affected more than the males [21]. Prevalence of iron deficiency with anemia is high in female than male this is due to menstruation especially in heavy menstrual blood loss greater or equal to $80 \mathrm{ml}$ per month [28]; the prevalence of iron deficiency anemia declined sharply in males after 16 years of age coinciding with the end of a growth spurt while the prevalence among females stated to rise after the age 18 years as they proceed to marriage and childbearing [29]. Other reasons for increased prevalence of iron deficiency anemia in female include; pregnancy and lactation [11] and tissue growth during pregnancy [30]. Hemoglobin variants does not influence iron deficiency anemia. Anemia in hemoglobinopathies is due to increase in the breakdown of red blood cell and not due to iron deficiency. As the red blood cells are frequently breakdown, there is conservation of hemoglobin iron which is then stored as ferritin. This confirms the normal serum iron and serum ferrtin level obtained in $\mathrm{Hb} \mathrm{SS}, \mathrm{Hb} \mathrm{SC}$ and $\mathrm{Hb} \mathrm{CC}$ compared to other hemoglobin variants despites the low values in hematological indices. Blood film morphology among diagnosed iron deficient anemic patients shows microcytic (low mean corpuscular volume), hypochromic (low mean corpuscular hemoglobin), anisocytosis (variation in size between red blood cells) and poikilocytosis (abnormally shaped red blood cells); this red cell morphology is due to depleted iron stored and hemoglobin concentration [7,31].

\section{Conclusion}

Iron deficiency is the most common cause of anemia worldwide. This study showed that, iron deficiency anemia was common in both children and female of child bearing age and iron status in anemic patients with hemoglobinopaties were adequate.

\section{Recommendation}

The appropriateness of investigating patients who are frail and/or have significant co-morbidity needs to be considered on an individual basis. The severity and nature of the anemia should be weighed against the risk of bowel preparation and whether the patient is fit enough to withstand treatment (if a colorectal cause was found). Adolescents should be encourage, particularly those with risk factors for iron-deficiency anemia, to follow the dietary strategies. Adolescents who are at high risk for anemia, such as female athletes with heavy menses, may benefit from routine or periodic use of a low dose iron supplement. This study will educate the public on the preventive measures against iron deficiency anemia in our society.

\section{Indication for Further Studies}

Additional parameters such as serum transferrin saturation, soluble transferrin receptor, reticulocyte hemoglobin, hypochromatic erythrocytes, erythrocyte or zinc protoporphyrin, Hepcidin and - if possible - bone marrow pull for iron staining can be assessed to diagnose iron deficiency anemia.

\section{References}

1. Centers for disease control and prevention (1998) Recommendations to prevent and control iron deficiency in the United States. MMWR Morbidity and Mortality Weekly Report. US Department of Health and Human Services, Centers for disease control and prevention, Atlanta, Georgia, USA.

2. World Health Organization (2005) Worldwide prevalence of anaemia 19932005. WHO Global Database on Anaemia. In: de Benoist B, McLean E, Egli I, Cogswell M (eds.). World Health Organization, Geneva, Switzerland.
3. Provan D (1999) Mechanisms and management of iron deficiency anaemia Br J Haematol 105: 19-26.

4. Wharton BA (1999) Iron deficiency in children: detection and prevention. $\mathrm{Br} J$ Haematol 106: 270-280.

5. Beard JL (2001) Iron biology in immune function, muscle metabolism and neuronal functioning. J Nutr 131: 568-579.

6. Alexandria VA (1996) Screening for iron deficiency anaemia including iron prophylaxis. Guide to clinical preventive series $\left(2^{\text {nd }}\right.$ edn), International medical publishing, London, UK. Pg no: 231-246.

7. Bothwell TH (1995) Overview and mechanism of iron regular. Nutr Rev 53: 237-245.

8. Contran, Kumar, Collins (2003) Robbins pathologic basic of disease. Harcourt private limited, India. Pg no: 627-630.

9. Hall R, Maila RG (1985) Medical Laboratory Haematology, ( $2^{\text {nd }}$ edn), Butterworth \& company, Boston, USA. Pg no: 207-211.

10. Bagechi K (2004) Iron deficiency anaemia an old energy. East Mediterr Health J 10: 754-760.

11. Bothwell Th, Charton RW (1989) Iron deficiency in women. The nutrition foundation, Washington DC, USA.

12. Cook JD (1999) The measurement of serum transferrin receptor. Am J Med Sci 318: 269-276.

13. Cook J (1999) The nutritional assessment of iron status. Arch Latinoam Nutr 49: 11-14.

14. Yates JM, Logan EC, Stewart RM (2004) Iron deficiency anaemia in general practice: clinical outcomes over three years and factors influencing diagnostic investigations. Postgrad Med J 80: 405-410.

15. Cook (1992) Serum Tranferrin Receptor. A quantitative measure of body iron deficiency at department of medicine. University medical centre, Kansas City, USA.

16. Kern HB (2003) Automated machine (Humancount).

17. Cheesbrough M (2005) District laboratory practice in tropical countries. Cambridge University Press, Cambridge, UK. Pg no: 247-258.

18. Ogamba AS (1998) Advanced instrumentation in water analysis (atomic absorption spectrophotometry; Buck 200 model).

19. Ozoegwu PN, Onwurah AE (2003) Prevalence of heamoglobinopathy and malaria disease in the population of old Aguata Division, Anambra State, Nigeria. Biokemistri 15: 57-66.

20. Idris M and Anis-Ur-Rehman (2005) Iron deficiency anaemia in moderate to severely anaemia patients. J Ayub Med Coll Abbottabad 17: 45-47.

21. Patel S, Shah M, Patel J, kumar N (2005) Iron deficiency anaemia in moderate to severely anaemia patients. Gujarat Medical Journal 64: 2 .

22. Hanif E, Ayub M, Anwar M, Ali W, Bashir M (2005) Evaluation of serum transferrin receptor concentration in diagnosing and differentiating iron deficiency anaemia from anaemia of chronic disorders. J Pak Med Assoc 55: 13-16.

23. Kilinç M, Yüregir GT, Ekerbiçer H (2002) Anaemia and iron-deficiency anaemia in south-east Anatolia. Eur J Haematol 69: 280-283.

24. Al Dallal ZS, Hussian KM (2003) Impact of the national flour fortification program on the prevalence of iron deficiency and anaemia among women at reproductive age in the kingdom of Bahrain (First monitoring study). Public health Directorate Nutrition Section, Ministry of health, Kingdom of Bahrain, World Health Organization, Cairo, Egypt.

25. Johnson-Spear MA, Yip R (1994) Hemoglobin difference between black and white women with comparable Iron status: justification for race-specific anemia criteria. Am J Clin Nutr 60: 117-121.

26. Looker AC, Dallman PR, Carroll MD, Gunter EW, Johnson CL (1997) Prevalence of iron deficiency in the United States. JAMA 277: 973-976.

27. Heath AL, Fairweather-Tait SJ (2002) Clinical implications of changes in the modern diet: Iron intake, absorption and status. Best Pract Res Clin Haematol 15: 225-241. 
Citation: Esan AJ (2016) Prevalence and Evaluation of Iron Deficiency Anemia in Anemic Hospitalized Patients in Osogbo, Nigeria. J Hematol Blood Transfus Disord 3: 007 .

- Page 6 of 6 •

28. Finch CA, Cook JD (1984) Iron deficiency. The American Journal of Clinical Nutrition 39: 471-477.

29. Mousa ZA, Prakash P, Jackson RT, Raqua MA (2003) A comparison of selected nutrient intakes in anemic and nonanemic adolescent girls in Kuwait. Nutrition research 23: 425-433.
30. Hallberg L (1988) Iron balance in pregnancy, In: Berger $H$ (ed.). Vitamins and mineral in pregnancy and lactation. Raven press, New York, USA. Pg no: $115-127$.

31. Brinkmann T, Simon-loperz R (2006) Latent iron deficiency need for new parameters to aid diagnosis. BMS 13: 803-805. 